\title{
Industrial Region: Evolutionary and Innovational Ways of Creation of Competitive Advantages
}

\author{
Eugeny Mihajlovich Krasavin ${ }^{1} \&$ Raisa Aleksandrovna Krasavina ${ }^{1}$ \\ ${ }^{1}$ National Research University Higher School of Economics, Nizhny Novgorod, Russian Federation \\ Correspondence: Eugeny Mihajlovich Krasavin, National Research University Higher School of Economics, \\ Bolshaya Pecherskaja str., 25/12, Nizhny Novgorod, 603153, Russian Federation. E-mail: ekrasavin@hse.ru
}

Received: November 20, 2014

Accepted: December 20, 2014 Online Published: February 25, 2015

doi:10.5539/ass.v11n6p302

URL: http://dx.doi.org/10.5539/ass.v11n6p302

\begin{abstract}
The paper presents competitiveness of the region as a dynamically-oriented system with a specific definition of objectives and adaptive "internal" environment. The long-term dynamics of competitiveness "external" environment is related with the theory of "major cycles" by N. D. Kondratyev through a contradictory influence of the "state" and "development" factors on the territorial productive powers with specified "growth points" and development stages. Structural model of competitiveness of the region is presented as interactive "center of perspectives" and "productive periphery" with effective feedback. Algorithm of transition from the basic competitiveness to the growth one based on qualitative and quantitative changes in efficiency of applied labour under multiple influences is specified in the paper. Possible formation of the regional competitiveness by evolutionary and innovational ways in terms of industrial region with intended effects from specific implementation of competitive advantages is shown herein.
\end{abstract}

Keywords: competitiveness of the region, basic competitiveness, prospective competitiveness, competitive advantages, competitiveness system

\section{Introduction}

Competitiveness of the territory means ability to compete with the other regions for limited resources and ways of utilizing them, for access to the national and world markets. Use of microeconomics competitiveness machinery in the regional science (Isard, 1960) gave impulse to federalism economics as competitiveness of different authorities (Tiebout, 1956), some subjects of the social sector theory (Stiglitz, 1988) and new federalism (Qian \& Weingast, 1996).

Cluster of definitions "competitiveness of the region" in Russian scientific literature restricts the phenomenon to interrelated features: dynamics and specific position in domestic and foreign markets (Novoselov, 1996); efficiency of utilization of regional resources and possibility to ensure production of competitive goods and services (Merkushev, 2004); ability of state and market institutions to create effective mechanisms to transform comparative advantages into competitive ones (Kovalenko, 2005); readiness to adapt and change conditions, to search and protect local competitive advantages, to support and improve positions of the regional economy in global competitiveness. Approach with the key role of innovative changes in economic landscape of the region based on resource flow turbulence, decrease of goods and innovations life-cycles, information richness, speed of implementation of organizational and managerial decisions inherent in globalization and transferred to the regional level is to be acknowledged as productive.

As a result, competitiveness of the region is to be considered as oriented system with specific goal and adaptive internal environment. With a view to universally recognized experience, these are consecutive, permanent steps for positive changes of quality of life based on the synergy effect.

\section{Methods}

Competitiveness of the region was presented as a result of interrelations of "external" and "internal" environment in order to form competitive advantages of the territory.

"External environment" of competitiveness of the region was studied by means of "major cycles" model (Kondratyev, 1993) with a view to: a) trend changes; b) long-term cyclic changes. On the basis of the historiographical analysis areas of concentration of the most distinctive production forms in different Kondratyev 
cycles were determined: progressive changes in technical-and-technological structure of the applied stock capital; industrial allocation schemes by periods of review; innovative growth "points" (Perroux, 1961); contradictions in interactions between competitive and sole regulators. Factor analysis resulted in determining two groups of factors promoting development of the region: "state" and "development" factors (Polynev, 2010). It is significantly that factors correspond to the region competitiveness level and act towards evolution according to the "herringbone" method (Ishikawa, 1985). It was found out that coincidence of factors impact results in formation of "the growth point" in the region based on transfer of absolute advantages into relative ones (Polynev, 2010). Counterphase is characterized by potency depression at appearance of real competitive advantages.

At superposing effect of factors complex to the results of automatic cyclic fluctuations one may notice distinctive structural changes in economic systems, which form territory competitiveness development trends (Table 1). They, in turn, promote start-up of the self-supported mechanism (innovations-production-innovations) and appearance of "the territories of growth" reflecting temporary non-replicated changes.

Table 1. Basic conditions for competitiveness of the regions

\begin{tabular}{|c|c|c|c|c|c|}
\hline $\begin{array}{l}\text { Competitive } \\
\text { regions }\end{array}$ & $\begin{array}{l}\text { Kondratyev major cycles } \\
1^{\text {st }} \text { cycle }\end{array}$ & $2^{\text {nd }}$ cycle & $3^{\mathrm{d}}$ cycle & $4^{\text {th }}$ cycle & $5^{\text {th }}$ cycle \\
\hline State factors & $\begin{array}{l}\text { Economical-geographical } \\
\text { position, concentration of } \\
\text { production and capital }\end{array}$ & $\begin{array}{l}\text { Mobility and } \\
\text { quality of } \\
\text { production } \\
\text { factors }\end{array}$ & $\begin{array}{l}\text { Diversification } \\
\text { of production } \\
\text { and capital }\end{array}$ & $\begin{array}{l}\text { Structure and } \\
\text { organization of } \\
\text { production }\end{array}$ & $\begin{array}{l}\text { Specialization } \\
\text { and } \\
\text { cooperation of } \\
\text { sectors }\end{array}$ \\
\hline $\begin{array}{l}\text { Development } \\
\text { factors }\end{array}$ & Industrialization & Location & Cooperation & Agglomeration & Integration \\
\hline Distinctive & Pole & & Adaptive & & \\
\hline changes & & Transformation & & Accumulative & \\
\hline $\begin{array}{l}\text { "Territories } \\
\text { of growth" }\end{array}$ & $\begin{array}{l}\text { Areas of } \\
\text { specialization }\end{array}$ & $\begin{array}{l}\text { Areas of } \\
\text { factory } \\
\text { concentration }\end{array}$ & $\begin{array}{l}\text { Complex } \\
\text { treatment } \\
\text { centers }\end{array}$ & $\begin{array}{l}\text { High-volume } \\
\text { line production }\end{array}$ & $\begin{array}{l}\text { Scientific and } \\
\text { production } \\
\text { complexes }\end{array}$ \\
\hline
\end{tabular}

The Table was compiled based on the following references: (Lipets, Pulyarkin, \& Schlichter, 1999; Baburin \& Mazurov, 2000; Grinin, Korotaev, \& Tsirel, 2011).

Intra-cyclic fluctuations are presented as a staged process with successively changeable basic resources (factors of production, investments, innovations, stock of tangible wealth) and effects (extensive, intensive, innovative economic growth, slowdown) (Porter, 1998). These changes enabled to determine limits of possible changes of the regional competitive environment, and the main vehicle for changes.

System analysis was applied (Bertalanfy, 1962) at modeling "internal" environment of the regional competitiveness, which enabled to mark out the following structural points: a) "a core" as a complex of long-run objectives ensuring life quality target growth and initiating adaptive transformations; b) "a periphery" ensuring different and productive relations with "external" environment and between system elements; c) "strategic level" supporting system integrity, setting the pace and direction of development, controlling the strategy. Mechanism of functioning is based on limitations of competitiveness objects (economic resources and access to the markets) and acts on the basis of transfer of absolute advantages to relative ones. The specified goal is to get benefit in terms of material (product and service growth) and non-material (image) competitive advantages. As a result, functioning of the regional competitiveness system may be presented by the following stepwise procedure: 1) formation of long-run objectives complex; 2) determination of labour forces parameters; 3) determination of directions for interregional competitiveness; 4) main subject strategies; 5) creation of cluster relations; 6) record of rate of changes. On all stages it is necessary to record time limits for the process of "leaving the competitors behind" that is connected with possible duplication of conditions and procedures in interregional competitiveness.

Application of above-mentioned and alternative methods resulted in possible study of the industrial region competitiveness as an algorithm for transition from the initial to the long-run competitiveness. It was assumed that transition into the state of competitiveness of the region is an adjustable and regulated (Kuznetsova \& Kuznetsov, 2012), multiversion process constituting leading creation of absolute advantages with stepwise progress towards relative advantages and synergy overall effect. 


\section{Key Findings}

\subsection{Analysis of the Industrial Region Competitiveness}

Choice of the industrial region as a research object proceeds from the practical need to simulate the regional competitiveness transition period from "the territory of growth" of the $4^{\text {th }}$ Kondratyev cycle to the postindustrial development region. Nizhny Novgorod region RF became a good example (Gradov, Kuzin, Mednikov, \& Sokolitsyn, 2003).

Post analysis showed that industrial region has: a) formed competitive advantages of the previous development period in terms of specialization in machine-building with the belt-line production centers; $b$ ) some entrances to the national markets of producer goods and intermediate products; c) monopoly of some plants; d) substantial scientific-and-production basis.

Destruction of administrative monopolism and extension of market relations involved the following activities in the region: transformation of competitiveness system in terms of changing "prospects core" with targeted settings of the $5^{\text {th }}$ Kondratyev cycle; orientation towards the integration "development" factors; records of new production and scientific forms; adjustment of market economic conditions and variety of forms of ownership.

Experience of competitive industrial regions (Porter, Takeuchi, \& Sakakibara, 2000) shows that their dynamics is characterized by special combination of "state" and "development" factors. Initial base is formed by relatively stable "state" factors: economical-geographical position, management system, organizations, institutional relations, legal basis, accrued social capital and image of the region. Advanced competitiveness of the region is connected with variable "development" factors: changes in qualifying-educational structure of an aggregate worker and appearance of new professions; creation and implementation of innovation programs and strategic planning objectives; implementation of advanced R\&D; adoption of "economy of knowledge" results; opening of new markets and market niches to enter international differentiation of labor and maintain global competitiveness (Ohlin, 1967).

Content and status of "state" and "development" factors formed the region SWOT-analysis information base (Table 2).

Table 2. Competitive advantages SWOT-analysis. Nizhny Novgorod region

\begin{tabular}{ll}
\hline Strength: & Weakness: \\
- Advantageous economical-geographical position & - Insufficient transport infrastructure \\
- Developed scientific and production basis & - Lack of modern logistical centers \\
- High-grade research and educational institutions & - Lack of social investments \\
- Developed informational and financial infrastructure & - Consolidation of regional markets \\
- Relatively low business expenditures & - Weak small business sector \\
\hline $\begin{array}{l}\text { Opportunities: } \\
\text { - Investments into existing and new industrial-scientific } \\
\text { clusters }\end{array}$ & $\begin{array}{l}\text { Threats: } \\
\text { - Consumer goods demand center }\end{array}$ \\
$\begin{array}{ll}\text { - International expansion } & \text { - Obsolete basic assets of traditional productions } \\
\text { - Investments into educational system of pressure to the regional business of } \\
\text { specialization in hi-tech sectors }\end{array}$ & $\begin{array}{l}\text { international competitiveness } \\
\text { on Relatively low wages }\end{array}$ \\
\hline
\end{tabular}

SWOT-analysis of competitive advantages in Nizhny Novgorod region showed the following results:

- Economic-geographical position of the territory, available scientific and production potential and infrastructure of the industrial region may be considered as a basis for establishing the $5^{\text {th }}$ Kondratyev cycle competitive region;

- The below complex transition activities are necessary: a) update of the technical and technological production basis; b) clustering of field integration schemes;

- Sequential and controlled activities of the regional management with regard to existing risks are needed;

- It is necessary to make a strategy for industrial region development adapting it with balance of real limitations and mid-term opportunities; 
- It is necessary to determine complex of long-term objectives with positive changes in aggregate labor structure and quality as a critical condition for high-quality life in the region.

Due to these notes, there is a possible increase of regional competitiveness by evolutionary and innovational changes (Table 3).

Table 3. Evolutionary and innovational ways of creation of competitive advantages in Nizhny Novgorod region

\begin{tabular}{|c|c|c|c|}
\hline \multicolumn{2}{|c|}{ Evolutionary way (basic advantages) } & \multicolumn{2}{|c|}{ Innovational way (formed advantages) } \\
\hline Basis/factor & $\begin{array}{l}\text { Implementation } \\
\text { form/effects }\end{array}$ & Basis/factor & $\begin{array}{l}\text { Implementation } \\
\text { form/effects }\end{array}$ \\
\hline \multirow{2}{*}{$\begin{array}{l}\text { Economic-geographical } \\
\text { position/factor } \\
\text { density }\end{array}$} & $\begin{array}{l}\text { Transport and logistics } \\
\text { hub/extension effect }\end{array}$ & \multirow{2}{*}{$\begin{array}{l}\text { Intellectual } \\
\text { potential/comparative } \\
\text { factors }\end{array}$} & \multirow{2}{*}{$\begin{array}{l}\text { Scientific } \\
\text { educational } \\
\text { complex/"growth point" } \\
\text { effect }\end{array}$} \\
\hline & $\begin{array}{l}\text { Consumer goods } \\
\text { demand } \\
\text { center/multiplier effect }\end{array}$ & & \\
\hline $\begin{array}{l}\text { Scientific and production } \\
\text { potential/factor productivity }\end{array}$ & $\begin{array}{l}\text { Scientific and } \\
\text { industrial } \\
\text { clusters/synergy effect }\end{array}$ & $\begin{array}{l}\text { Accrued } \\
\text { capital/complex factors }\end{array}$ & $\begin{array}{l}\text { High quality life } \\
\text { area/"attraction" effect }\end{array}$ \\
\hline
\end{tabular}

Source: authors.

Experience shows that these trajectories complement each other and may be used in concerted strategy. But evolutionary changes aim at "revitalization" of accrued potential, and innovational changes aim at prospective changes of qualitative and time-dependent advance of competitors. Resource-driven economy needs such internal interrelations, which give rise to the synergy effect, in order to achieve long-term competitiveness results. For post-industrial period these are varied transfers between industrial and scientific communities.

\subsection{Evolutionary Trajectory for Creating Regional Competitive Advantages}

Two groups of the region basic advantages are realized on the evolutionary way of competitiveness creation: natural and accrued. The first group is based on economic-geographical position with necessary conditions of complexity, complement ability, potential diversification and vast area of top income population groups with stable and intensive demand. In the first case, the region may be developed as a transport corridor, in the second case-as an area of specialized medium-tech small and middle production plants. In the industrial region under consideration two ways of increasing regional competitiveness are implemented: construction of a transport-logistic hub on the Eurasian transport corridor and creation of the consumer goods demand center (Government Regulation, Nizhny Novgorod region, 2006). And here are some disadvantages of these strategies: first, they are ineffective in the frames of stable negative external influences; second, there is a mid-term risk of non-compensated expansion of adopted experience to neighboring regions; third, lack of natural resources potential dictates continuous need in its realization by the most costly ways.

At the same time, one can see realization of the region competitive advantages resulting from the accrued scientific-and-production base. It works under conditions of the more intensive resource-and-information support and requires: detailed reorganization and technical-technological re-equipment with saving specialization; different forms of scientific and industrial cooperation; more effective scientific and industrial transfer; R\&D quick replication and commercialization. Scientific and industrial clusters, where synergy effect is created from integration system of different-scale enterprises, quicker R\&D implementation, possible competitive products on external markets, attraction of foreign investors to the region serve as a modern form of realizing competitive advantages of the region. Industrial innovation cluster of motor industry and petrochemical industry, Sarovsky innovation cluster (Russian cluster observatory, 2012), serve as examples of clusters existing within the territory under consideration. They effectively implement integration of scientific and industrial sectors based on the product demand on the national and international levels.

It should be noted that involvement of a low-quality labor force into forms of production decreases post-industrial competitiveness of the region. Principles of competitiveness of new cluster structure are violated: low costs due to employment of qualified but cheap labor forces; employee multifunctionality; quick adaptation to changing "external environment". As a result, reacting factors set a lower "reference point" for the regional competitiveness and decrease "advance" time of competitive regions. Thus, study of the employee's regional characteristics showed: low productivity, low educational level (223 employees of 1000 have higher education), 
excessive specialization of employees, interregional migration activity of qualified personnel (Russian Federation Federal State Statistics Service, 2013).

It is determined that evolutionary way of positive competitiveness change transforms basic and accrued advantages of the region resulting in new quality of material capital organization and realization and efficiency growth. But, it does not alter drastically employee's characteristics as a non-reproducible advantage of the region.

\subsection{Innovational Trajectory of Forming Regional Competitive Advantages}

Innovational way of regional competitiveness development provides for connections with forming competitive advantages based on human capital assets, social capital and innovational infrastructure. The conditions for its realization are as follows: existing programs of maintaining education quality and its combination with practice, organizational and financial support of small innovational business, mass adoption of innovational behavior and professionalism. Realization of social capital requires increase of trust level in the society following generally recognized rules and values, use of social networks for self-organization and common activities. Innovational and industrial parks, scientific and educational complex as an uncopyable element of "economy of knowledge" are forms of realization of mentioned advantages. Such effect as "triple helix" self-supported mechanism (science-innovations-production) (Etzkowitz, 2012) is able to bring competitiveness of the region to the national and international standards level and to create an attractive brand of the innovational leader. A science park with scientific and educational base, pilot production, chain of small innovational enterprises-global leaders in ultrasonic equipment (MP Medusa), gyrotron production (MP GIKOM), medical optical tomography (MP Biomedtech)-was established in Nizhny Novgorod region on the basis of the Institute of Applied Physics of the Russian Academy of Science (Mechanic, 2010).

Scientific and educational complex of the region is substantial and produces competitive advantages such as: qualitative staffing needs service; high level R\&D in advanced fields of science, engineering and technology; creation of conditions for integration with production by means of mutual practices and pilot production; accumulation of intellectual capital and formation of an attractive regional brand. In our example, universities of the region lay the groundwork for competitive advantages as new generation of the specialists-carriers of high level knowledge and competences with creativeness. Nevertheless, general "nutrient" medium in the form of the small innovational business with real future projects and effective culture of competitive "consumption" of qualified specialists is not formed. Constraint factors are as follows: low level targeted investments into education, weak OF supportability, insufficient organizational basis for scientific and production cooperation, lack of complexity and continuity of educational process, weak development and productivity of the small innovational business. Thus, amount of man-power employed in the small business of the region $(35 \%$ of total man-power employed) does not comply with West European standards (50-60\%) (Mikhailov, 2014). At this, share of innovation-active organizations implementing technological, organizational, marketing innovations decreased from $18.4 \%$ (2009) to $15.4 \%$ (2013), number of organizations implementing R\&D in absolute units also slightly changed from 90 (2009) to 96 (2013) (Nizhegorodstat, 2013).

An obligatory component of innovational ways for development of regional advantages is creation in the region of the high life quality area that is understood as spatial behavior of the local society under the influence of external existence conditions complex. As a multilevel system this area is based on the block of interrelations of economy and policy with high welfare demands expressed in absolute and relative GRP. The second level presents combination of spheres responsible for blocks of "welfare", "security" and "freedom" with quality amenities expressed in the Human Development Index (HDI). Such parameters as employment, housing, social stability, self-realization acquire special meaning. The third level reflects satisfaction with life in this region and shows "effect of wellbeing"-created conditions of active society. The parameters here are such as lifetime and ecological and economic conditions. Cluster composition with valuable connections (science-innovations-production-society) that gives an effect of "social responsibility" is admitted for such area. In the region biomedical and recreation clusters, some health and environmental programs are being organized and implemented. But HDI dynamics indicates insufficient efforts of the region in terms of maintaining high quality life. (Report on human development in RF, 2013).

Innovational way of creating competitiveness of the region is characterized by preliminaries capacity, big non-material efforts, need in permanent performance control, need in demonstration effect.

\section{Discussions}

Thus, there are two interdependent ways of achieving competitiveness in the industrial region. First, way of evolutionary changes with gradual alteration of available production and scientific base, with cluster 
organization and formation of optimal value chain. Maximum results: growth of labor efficiency. Second, way of innovational changes with breakthrough alterations such as aggregate worker, with high value added, with formation of self-supporting scientific and production mechanism of regional development. Maximum results: high life quality.

It should be noted that both ways are restricted by resources and finances, and by time. Besides, drawbacks of the first one lie in "old" specialization and in divestiture of new organization forms under conditions of old technical-and-technological proportions and proven managerial decisions. Under such conditions, competitiveness increaser strategy turns to be unstable towards the negative external effects, aggressive influence of the regional and international competitors. Poor own resource potential is an additional negative condition for developing competitiveness, and it dictates continuous need of its implementation by the mostly costly ways.

Innovational way of creating competitive advantages has a long-term return and is connected, in our opinion, with transformation of relative advantages into non-reproducible similar ones. Authors connecting competitiveness of the region with the long-term economic growth have the same opinion (Charles \& Zegarra, 2014). Restrictions lie here in insufficient investments in "economy of knowledge", weak science-intensive basic funds, lack of complexity and continuity of educational process, weak informal transfer in the small and medium innovation business sector. Innovational way is connected with poor formatted parameters: creativity, trust, happiness. It is known that social capital realization requires high level impersonal trust in the society, and it's a result of complying with generally recognized rules and standards, values, that in its turn is a product of self-organization. In fact, there is a requirement to establish essential connections of economic and social phenomena.

Other approaches to formation of the regional competitiveness are presented by M. Porter, who considers them as a basis for stable cluster structures, which have better consistence with sources of achieving competitive advantages (Porter, 1998). Grounds in defend of separate study of competitiveness improvement ways are as follows: first, industrial region has another production structure with large-scale industry prevailing; second, there are some problems with transfer of the region to another level of competitiveness quality as opposed to efficiency increase based on combination of cooperation and competitiveness; third, it is necessary to record management activities in terms of qualitative change of both production factors and conditions of their application. Some authors (Castells, 2010) fairly criticize approach of one-to-one association of such definitions as "labor productivity" and "competitiveness of the region" and offers to use parameters of new technologies and fields for the latter one.

\section{Conclusion}

Study of the region as a complex system object theoretically results in the following: a) competitiveness of the region is determined as a goal-oriented system with adaptive "internal" environment subject to macroeconomic changes; b) dynamics of a competitive region subjects to long-term structural alterations, which are formed under the influence of "state" and "development" factors; c) structural theoretical model of competitiveness of the region has three elements, which form algorithm of transition from basic to prospective competitiveness by evolutionary and innovational ways.

Practical application of the theory in order to create competitiveness on a definite example of industrial region results in the following findings: competitiveness of the region may be achieved by evolutionary and innovational ways grounded on basic and formed advantages with different specific events and their effects.

On the whole one must admit necessity in parallel and maintaining use of both strategies for achieving stable competitive advantages of the region with possibility to be ahead of competitors in terms of time.

Further study of the subject is dictated by need in full review of structural and functional peculiarities of the regional competitiveness, basic conditions for development of competitive advantages of the region, factors promoting and preventing development of competitiveness in the region, ways and trajectories of regional competitiveness development. As a result, the following aspects of analysis are topical: competitiveness and resource potential of the region; competitiveness to labor productivity rate; competitiveness and life quality in the region. Special attention to these points would help the industrial territory to be out of doldrums.

\section{References}

Baburin, V., \& Mazurov, Y. (2000). Geographical grounds of management. Moscow: Delo.

Bertalanfy, L., \& Hall, A. (1962). A Methodology for Systems Engineering. Princeton: Nostrand.

Castells, M. (2010). The Rise of the Network Society. The Information Age: Economy, Society and Culture. Ch. 3. Wiley-Blackwell. 
Charles, Y., \& Zegarra, L. (2014). Measuring regional competitiveness through Data Envelopment Analysis: A Peruvian case. Expert Systems with Applications, 41(11), 5371-5381. http://dx.doi.org/10.1016/j.eswa. 2014.03.003

Etzkowitz, H. (2012). Triple Helix Travels. Innovation on the Move Helice, 1(1), 3-4.

Federal State Statistics Service. (n. d.). Retrieved November 29, 2014, from http://www.gks.ru/bgd/reg/b13 $14 \mathrm{p} /$ Main.htm

Government Regulation \#127 “On approval of Nizhny Novgorod region development strategy for till 2020”, Nizhny Novgorod region, ed. of 20.03.2009. (2006, April 17).

Gradov, A., Kuzin, B., Mednikov, M., \& Sokolitsyn, A. (2003). Regional economy. Saint Petersburg: Piter.

Grinin, L., Korotaev, A., \& Tsirel, S. (2011). In S. Y. Malkov (Ed.), Cycles of modern World-System development, Chapter 2. Moscow: Book house "LIBROKOM".

Isard, W. (1960). Methods of Regional Analysis: An Introduction to Regional Science. New York.

Ishikawa, K. (1985). What is Total Quality Control? The Japanese Way. London: Prentice Hall.

Kondratyev, N. (1993). In L. I. Abalkin, V. M. Bondarenko, V. V. Ivanov, \& S. L. Komlev et al. (Eds.), Selected works. Moscow: Economy.

Kovalenko, E. (2005). Regional economy and management. Saint Petersburg: Piter.

Kuznetsova, O., \& Kuznetsov, A. (2012). System diagnostics of economy of the region (3rd ed.). Moscow: Book house "LIBROKOM".

Lipets, Y., Pulyarkin, V., \& Schlichter, S. (1999). Geography of world economy. Moscow: Academic publishing center VLADOS.

Mekhanic, A. (2010). Mandelstam's successors. Expert, 34.

Merkushev, V. (2004). Integral assessment of competitiveness of the region. Collection of scientific papers of young scholars "Regional science” (Vol. 1). Moscow: SOPS.

Mikhailov, A. (n. d.). Small business: Time for success. Retrieved November 10, 2014, from http:/www.vremyan.ru/analitycs/

Nizhegorodstat: Data bases. (n. d.). Retrieved November 29, 2014, from http://nizhstat.gks.ru/wps/wcm/connect /rosstat_ts/nizhstat/ru/st

Novoselov, A. (1999). Regional markets. Moscow: INFRA-M.

Ohlin, B. (1967). Interregional and International Trade (Revised ed.). Cambridge, Massachusetts: Harvard University Press.

Perroux, F. (1961). Economy of the $20^{\text {th }}$ century. Moscow.

Polynev, A. (2010). Competitive opportunities of the regions: Methodology and ways of improvement. Moscow: KRASAND.

Porter, M. (1998). On Competition. A Harvard Business Review Book, Ch.2.

Porter, M., Takeuchi, F., \& Sakakibara, M. (2000). Can Japan Compete? Basic Books, Perseus Publishing, Cambridge, Massachusetts, Ch.3.

Qian, Y., \& Weingast, B. (1996). China's Transition to Markets; Market-Preserving Federalism, Chinese Style. Journal of Policy Reform, 1, 149-185. http://dx.doi.org/10.1080/13841289608523361

Report on human development in the Russian Federation 2013 "Stable development: Rio challenges". (n. d.). Retrieved November 29, 2014, from http://www.undp.ru

Russian cluster observatory: Data base. (n. d.). Retrieved November 29, 2014, from http://claster.hse.ru

Stiglitz, E. (1988). Economics of the Public Sector (2nd ed.). Princeton University: W. Norton \& Company.

Tiebout, C. (1956, October). A pure theory of local expenditures. Journal of Political Economy, 64, $416-424$. http://dx.doi.org/10.1086/257839

\section{Copyrights}

Copyright for this article is retained by the author(s), with first publication rights granted to the journal.

This is an open-access article distributed under the terms and conditions of the Creative Commons Attribution license (http://creativecommons.org/licenses/by/3.0/). 